\title{
Evaluation of Flood Risk Reduction Project at Tenggang River, Semarang City, Central Java Province, Indonesia
}

\author{
Nuon Udom \\ Sangkat Tuk Laak III, Khan Tuol Kork, Phnom Penh, CAMBODIA \\ nuon@mail.ugm.ac.id
}

\begin{abstract}
Evaluation of flood risk reduction at Tenggang River is needed to reduce the urban and coastal flood from high-intensity rainfall and sea level rise. This paper mainly discusses rainfall frequency analysis, simulation of hydraulic structure performed by HECRAS 5.0.3, and the proposed alternative flood mitigation for 25-year flood return period. Hydrology and hydraulic was analyzed to investigate the flooding risk. The result of simulation illustrated the improvement channel condition by normalization the riverbed and the increase of levee to solve flood inundation at Tenggang River using the designated flood return period (25 years of return period, $\mathrm{Q}_{25}=119 \mathrm{~m}^{3} / \mathrm{s}$ ). The result of simulation showed that the hydrologic-hydraulic modeling is acceptable compared to the report from the office of public work in Semarang City.
\end{abstract}

Keywords: Frequency analysis, flood risk reduction, alternative flood mitigation

\section{INTRODUCTION}

Flood which is one of the damaging natural disasters has resulted in relentless destruction, economic difficulty, and casualties (Han \& Coulibaly, 2017). There are various causes that generate floods such as, rainfall floods in the winter, tidal floods, rising groundwater floods, urban sewer flood or dam break floods.

Tenggang River located in Semarang City has suffered from heavy rainfall and coastal floods for years. Coastal flood in combination with high tide occurs due to tidal movement, wave action and accelerated sea level rise because of climate change cause rob flooding (Marfai \& King, 2008). Tidal flood in Semarang is also worsened by land subsidence induced by overexploitation of groundwater and rapid development in Tenggang area.

Semarang as part of the global community is also affected by sea level rise. According to the Asia-pacific network for global change research, the present worldwide sea level rise (SLR) is roughly $2 \mathrm{~mm}$ per year (1-3 mm/year in the coastal areas of Asia) and is predicted to significantly rise to approximately $5 \mathrm{~mm}$ per year over the next one hundred years. These alterations will have to major effect on tidal inundation in low-lying coastal areas of the city. The mixture of the impact on land use, climate change, and land subsidence against flooding and tidal inundation resulted in the management of the drainage system in the city of Semarang yet to be completed. Tanggang
River is located on the northern side of Semarang city as shown in Figure 1.

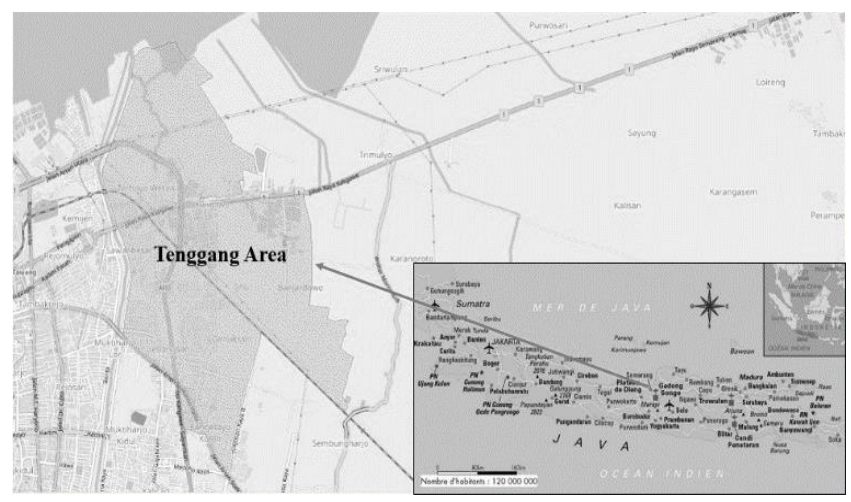

Figure 1. Study area.

Some researchers have been conducted the study on flooding at Semarang city. The researcher conducted research on flood mitigation and flood mapping near the Tenggang River. The purpose of this research is to create the flood distribution map and flow velocity distribution map of BKT River with existing condition channel and normalization condition channel. In this study, the result showed that improving channel condition by normalization can be achieved by reducing flood inundation at BKT River for 2 years flood by $47.44 \%$ and 5 years flood by $52.83 \%$. In addition, another researcher has also conducted research regarding flood mitigation along Banger River near east floodway in Semarang City. This study focused on how to design the polder systems, by normalizing Banger River channel, levee, jetty, pond and other structural measures. It analyzed the effect of 
Dombo Sayung floodway in reducing the flood discharge at Babon River and Dolok River by using HEC-RAS version 3.1. The design flood as the input of simulation at the upstream uses several return periods of $\mathrm{Q}_{2}, \mathrm{Q}_{5}, \mathrm{Q}_{10}, \mathrm{Q}_{20}, \mathrm{Q}_{50}$ respectively. The above study showed that the Dombo Sayung floodway reduces the spill over along Babon and Dolok River banks by $2.62 \%-59.45 \%$ depending on the flood discharge.

\section{HYDROLOGY AND HYDRAULIC MODEL}

\subsection{Hydrology}

In the context of science, hydrology is the study of water that is closely linked to the space-time-frequency features of the quantity and quality of the waters of the earth in relation to their existence, distribution, movement, catchment, and development. Hydrology plays a significant role in dealing with many issues relevant to environmental and ecological management and social development. Rainfall-runoff modeling is the prominent solution which, in particular, is used in water resources assessment, flood and drought mitigation, and water resources planning and management.

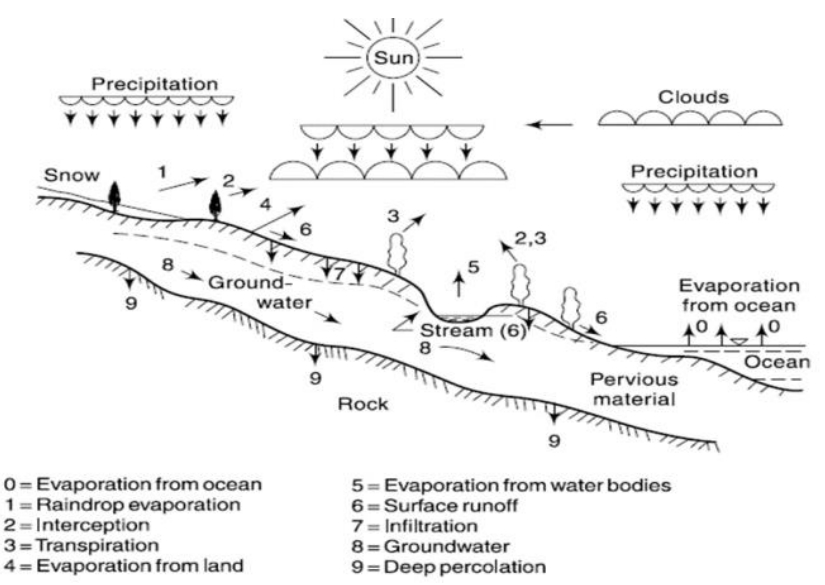

Figure 2. Hydrology cycle (Subramanya, 2008)

Water comes to the earth in all its three states liquid, solid and gaseous and in various degrees of motion. Evaporation of water from water bodies such as oceans and lakes, formation and movement of clouds, rain and snowfall, streamflow and groundwater movement are examples of the dynamic aspects of water. The various aspects of water related to the earth can be explained in terms of a cycle known as hydrologic cycle as shown in Figure 2 (Subramanya, 2008).

\subsection{Watershed}

A watershed is a plot of land that flows out to all the streams and rainfall to an ordinary outlet like the outflow of a water storage, mouth of a bay, or the regions in the stream channel. Watershed is occasionally used interchangeably with drainage basin or catchment. Ridges and hills that split two watersheds are known as drainage divide. The watershed is composed of surface water lakes, streams, reservoirs, and wetlands and all the underlying groundwater. Huge watersheds consist of a range of smaller watersheds. It totally relies on the outflow point; a region that flows water out to the outflow regions is considered as the watershed for that outflow location ( see Figure 3).

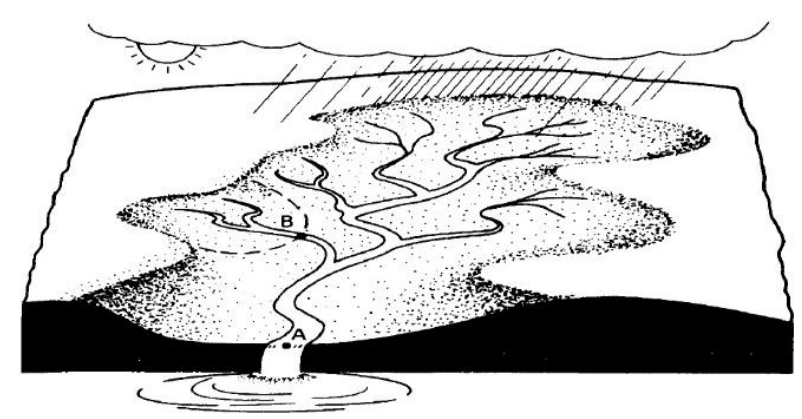

Figure 3. Watershed (Subramanya, 2008)

\subsection{Hydrograph}

Hydrograph is a graphical representation of the discharge of a stream as a function of time. To identify general runoff characteristics and provide a basis for the analysis of a graphical presentation of stream flow, the data is prepared in the form of hydrographs.

\subsection{Hydraulic modeling}

The hydraulic model used was the one-dimensional HEC-RAS 5.0.3 under gradually varied, steady, mixed flow. Actually, this model calculates water height from a flow value. Therefore, we applied it iteratively, trying tentative peak flows until the difference between the modeled water height and the actual flood mark was smaller than $1 \mathrm{~cm}$. The HEC-RAS model needs input data including geometry channel (cross sections shape and channel longitudinal slope) given by the cross sections of the digital terrain model, roughness coefficient corresponding to the type of surface (Chow, et al., 1988), as well as boundary and initial conditions.

\section{MATERIALS AND METHODS}

\subsection{Hydrology analysis}

Rainfall analysis is needed for calculation of runoff flood discharge. To get the quality of rainfall in a region can be calculated by some of the following methods, such as arithmetic mean, Thiessen polygon and Isohyet. Thiessen polygon method is suitable for the use to obtain the catchment rainfall of three stations at Tenggang River where are Karangroto station, 
Simongan station, and Pucang Gading station. The goodness of fits was selected for rainfall distribution. Thiessen polygon is illustrated in the equation: (Raghunath, 2006).

$$
P_{a v e}=\sum_{i=1}^{n} \alpha_{i} P_{i}
$$

where $P_{\text {ave }}$ is an average of watershed rainfall (mm), $P_{i}$ is rainfall depth at each station, $\alpha_{i}$ is the weight of station $i$.

For Engineers, hydraulics and hydrology are frequently required to derive design values on hydrologic events, such as flow discharge or rainfall depth. The frequency analysis, the statistical method which applies to time series data is common practice to fit those data to the theoretical probability distributions. It uses cumulative distribution function of the selected probability distribution to predict the magnitude of hydrology event. Additionally, the frequency analysis defines the design values based on the magnitude of the hydrologic event having a particular probability of occurrence.

The parameter statistic such as statistic standard deviation, mean, variance and Skrew for computing four distributions such as Normal distribution, Lognormal distribution, Gumbel distribution and Log Pear type III distribution which is determined by analyzing the rainfall depth design. Goodness of fit test is used for testing this distribution (McCuen, 1998).

Chi-square test: $\chi^{2}=\sum_{i=1}^{M}\left[\frac{\left(X_{m}-N_{P m}\right)^{2}}{N_{P m}}\right]$

where $\chi^{2}$ is Chi-square value, $X_{m}$ is expected frequency for class, $N_{P m}$ is illegible frequency on class, $M$ is number of class.

Smirnov-Kolmogorov Test:

$$
\Delta_{\max }=\max |\operatorname{prob}(Y<y)-\operatorname{Pr} o b(Y<y)|
$$

It is rejected if $\Delta_{\max }<D_{c}$ while $D_{c}$ is critical value according to the Smirnov-Kolmogorov table.

The rainfall intensity is calculated using Mononobe formula (Laksana, 2015).

$$
I_{t}^{T}=\left(\frac{R_{t}^{T}}{X}\right)\left(\frac{X}{t}\right)^{\frac{2}{3}}
$$

where $I_{t}^{T}$ is rainfall intensity at t hour, $R_{t}^{T}$ is rainfall on $T$ return period with duration of $X$ hour, $X$ is rainfall duration.

Rational equation is one of the oldest methods, and it was used to estimate peak discharge at first (Wanielista, 1990). Empirical equation of Rational method is:

$$
Q=0.278 \times C I A
$$

where $Q$ is peak discharge $\left(\mathrm{m}^{3} / \mathrm{s}\right), C$ is the runoff coefficient, I am the rainfall intensity $(\mathrm{mm} / \mathrm{h})$ and $A$ is watershed area $\left(\mathrm{km}^{2}\right)$. In this case study the Rational method has been modified in order to determine the flow hydrograph.

\subsection{Hydraulic analysis}

In this research, for hydraulic simulation, three scenarios of 1-D of unsteady flow analysis has been done by using HEC-RAS version 5.0.3 for hydraulic flood routing as shown in Figure 4.

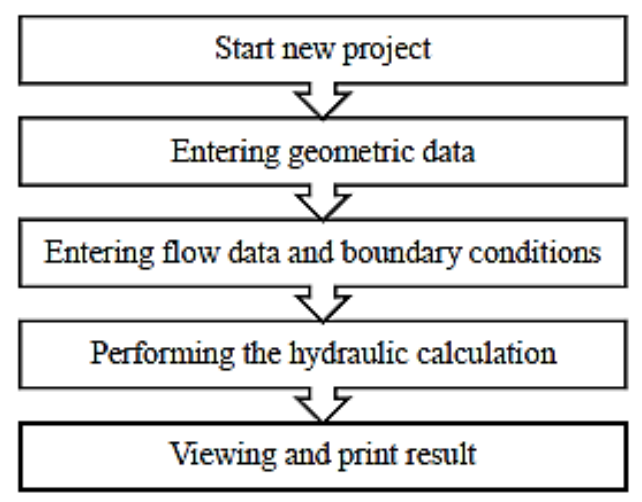

Figure 4. Schematic hydraulic simulation in HEC-RAS.

\subsection{River geometry of Tenggang River}

River geometry data used for simulating the existing condition of Tenggang River was shown in Figure 5. The hydraulic structure such as bridges structures was not taken into account of the hydraulic simulation.

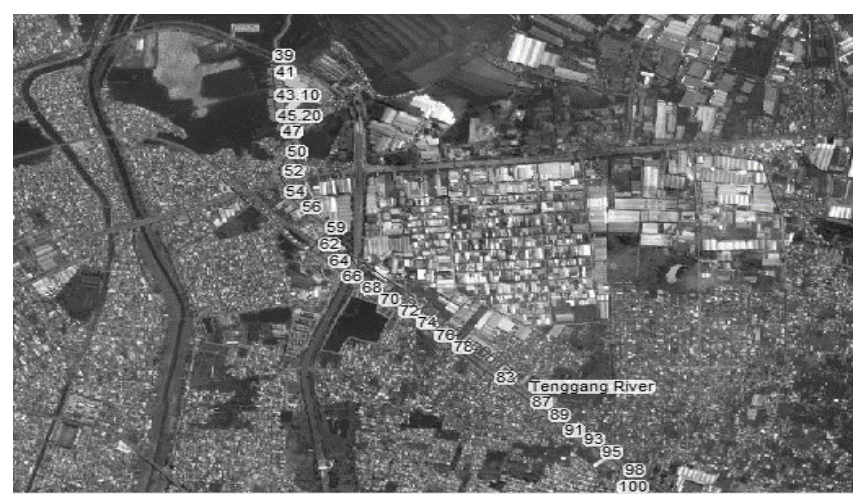

Figure 5. River geometry of Tenggang River. 


\subsection{Boundary condition}

The hydrographs of sub-catchments were distributed as uniform lateral inflow to the drainage system. The flow hydrograph was applied to the upstream flow of the Tanggang River. The lateral inflow was applied to all sub-catchments such as in Tributary River, Pacang River, upstream and downstream. From station TG.39 to TG.100 was selected for simulating of flood movement and from the River station, TG.0 to Station TG.38 is neglected in this research, because all of these stations are the coastal area.

\section{RESULTS AND DISCUSSION}

\subsection{Rainfall simulation}

Three rainfall stations were analyzed, i.e. Simongan rainfall station, Karangroto rainfall station, and Pucang Gading rainfall station. According to Thiessen diagram, two rainfall stations, namely Simongan and Karangroto gauge covered larger area than another station which are 10.473 ha and 1127.477 ha, respectively Because the area affected by Simongan station is too insignificant compared to Karangroto, Therefore, it can be assumed that Karangroto station is the exclusive factor influencing Tenggang area (see Figure 6). The results of the maximum daily rainfall was obtained as shown in Table 1.

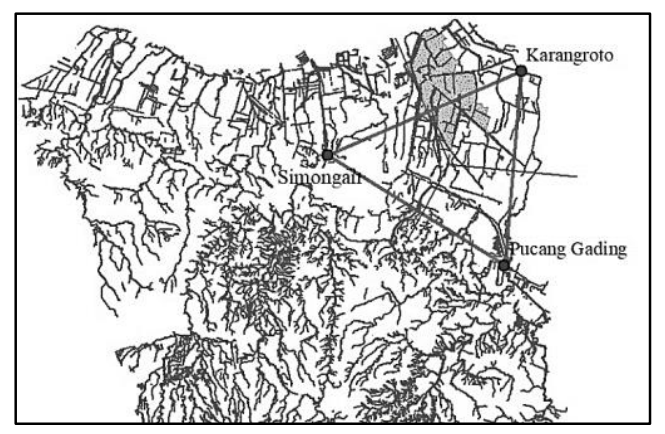

Figure 6. Thiessen polygon of three stations.

Table 1. Maximum daily rainfall

\begin{tabular}{llll}
\hline Year & $\begin{array}{l}\text { Max daily } \\
\text { rainfall }(\mathrm{mm})\end{array}$ & Year & $\begin{array}{l}\text { Max daily } \\
\text { rainfall }(\mathrm{mm})\end{array}$ \\
\hline 1991 & 83.2 & 1999 & 88.8 \\
1992 & 59.3 & 2000 & 118.1 \\
1993 & 126.9 & 2003 & 79.5 \\
1994 & 48.1 & 2004 & 142.2 \\
1995 & 87.2 & 2005 & 56.2 \\
1996 & 50.4 & 2006 & 171.6 \\
1997 & 78.5 & 2007 & 100.6 \\
1998 & 59.7 & 2008 & 171.9 \\
1999 & 88.8 & 2009 & 128.83 \\
2000 & 118.1 & 2010 & 124.2 \\
2001 & 81.0 & 2011 & 99.1 \\
2002 & 47.0 & & \\
\hline
\end{tabular}

\subsubsection{Frequency analysis}

Frequency analyses were analyzed by Gumbel, LogNormal, Log Pearson type III and Normal Distribution. Goodness of fit test was the method of selecting the best distribution for available 20 years with Chi-square test and Smirvon-Kolmogorov test by using confident level of 0.9 . The result of analyses was shown Log-Normal distribution is accepted with designing $171 \mathrm{~mm}$. The result of all method were shown in Figure 7.

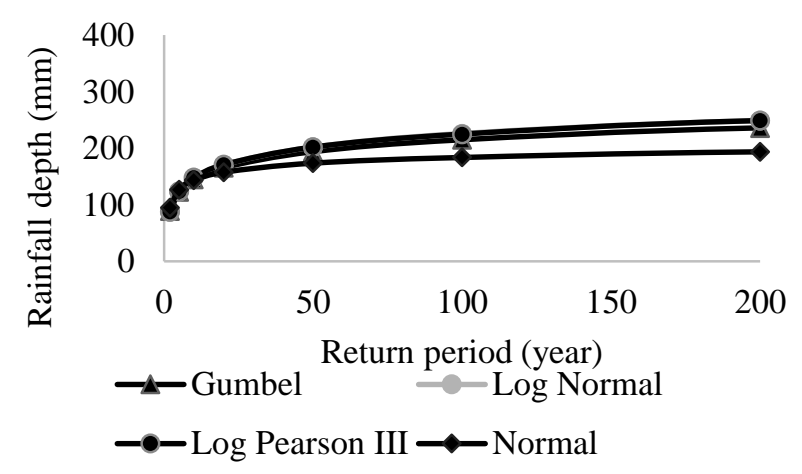

Figure 7. Result of return period with all methods

\subsubsection{Uniform lateral inflow}

Inflow along Tenggang River is assumed as rainfall that uniformly distributed all over basin. calculating inflow for this condition can be calculated with the Rational method. After divide basin into four sections, lateral inflow can be calculated by using the Rational method. Area and inflow of each section are presented in Table 2.

Table 2. Uniform lateral inflow Tenggang River

\begin{tabular}{llllll}
\hline Location & $\begin{array}{l}T_{c} \\
(\mathrm{~h})\end{array}$ & $\begin{array}{l}\text { Area } \\
\left(\mathrm{km}^{2}\right)\end{array}$ & $C$ & $\begin{array}{l}I \\
(\mathrm{~mm} / \mathrm{h})\end{array}$ & $\begin{array}{l}Q_{25} \\
\left(\mathrm{~m}^{3} / \mathrm{s}\right)\end{array}$ \\
\hline Upstream & 1.0 & 3.55 & 0.9 & 59.98 & 53.27 \\
Downstream & 1.0 & 3.37 & 0.7 & 59.98 & 39.33 \\
Pacang & 1.0 & 1.07 & 0.9 & 59.98 & 16.06 \\
Tributary & 1.0 & 3.37 & 0.9 & 59.98 & 50.57 \\
\hline Total & & & & & 119.90
\end{tabular}

In order to perform unsteady flow in HEC-RAS need to transform peak flow from a rational method into flow hydrograph by modifying the rational method. The flow hydrograph can be obtained from the Figure 8 .

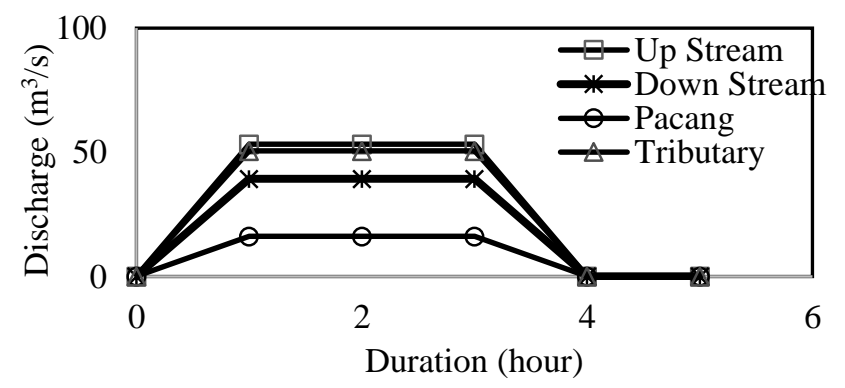

Figure 8 . The 25-year flood hydrograph. 
According to the graph above we can see that the maximum runoff of design rainfall 25-year return period is varied $\mathrm{m} 16.06 \mathrm{~m}^{3} / \mathrm{s}$ to $53.27 \mathrm{~m}^{3} / \mathrm{s}$. And these flood hydrographs have been used to estimate the section of drainage system along Tenggang River and also applied as the boundary condition and uniform lateral inflow to compute flood routing in HEC-RAS model.

\subsection{Results of simulation in each scenario}

\subsubsection{Existing condition}

The mean surface of the water is higher than the slope of the River. The elevation of the riverbed in the upstream is 0.01 up to -2.5 at the downstream. The slope of the riverbed is not effective; thus, the rainfallrunoff does not smoothly flow along the river to the downstream, besides high tide from the sea itself also blocks the flow at the downstream. In this case, the designing of flood 25 years period is over bank in some of the cross sections of Tenggang River. Mostly it occurs in the middle and the downstream of Tenggang River. The water surface profile of existing condition of Tenggang River was shown in Figure 9.

According to graph above in Figure 10, the flood has been inundated $12 \mathrm{~h} 02 \mathrm{mn}$ by using $24 \mathrm{~h}$ running time simulation, where the high of river bank at downstream is $-0.02 \mathrm{~m}$ MSL (mean sea level), flood started from 06:00 until 18:02 at the high $0 \mathrm{~m}$ to $0.5 \mathrm{~m}$ and goes down to $-0.01 \mathrm{~m}$.

\subsubsection{Riverbed normalization}

In this scenario, the flood still occurs due to the flow discharge is big, $\mathrm{Q}=119 \mathrm{~m}^{3} / \mathrm{s}$. This scenario focuses on making the cross-section in a rectangle, making the slop riverbed as smoothly than before for increasing the flow of rainfall runoff to the downstream. The width of cross section and the levee still constant like in existing condition. Figure 11 illustrates about water surface profile after normalizing river bed. After normalizing riverbed, flood still occurs. Figure 12 illustrates the cross-section after normalization riverbed. It shows that in Tanggang River RS 73, the flood is overbank $0.5 \mathrm{~m}$. The width of this cross section is $7 \mathrm{~m}$ and the height of this cross section $1.3 \mathrm{~m}$.

\subsubsection{Increase width, and design levee}

The purpose of the second scenario about riverbed normalization cannot solve the flood problem. Thus, the third scenario needs to be proposed by increasing the width of cross section and design the new levee to protect the flood overbank see in Figure 13. After doing normalization of river bed with slop 0.0005 and increase levee with the freeboard $0.8 \mathrm{~m}$, and enlarge the width of the drainage system. The width has been increased from $7 \mathrm{~m}$ to $10 \mathrm{~m}$. The height has been increased from $1.3 \mathrm{~m}$ to $1.98 \mathrm{~m}$. The maximum water surface of flood 25 years returns period in this crosssection goes up to the elevation +1.2 . By increasing the levee of freeboard $0.8 \mathrm{~m}$, the flood cannot flow out of the riverbank. So, it can be solved the flood inundation with the 25 years return period at Tenggang area. The result of normalization riverbed, enlarge the crosssection and increase levee at TG.74 can be seen in Figure 14.

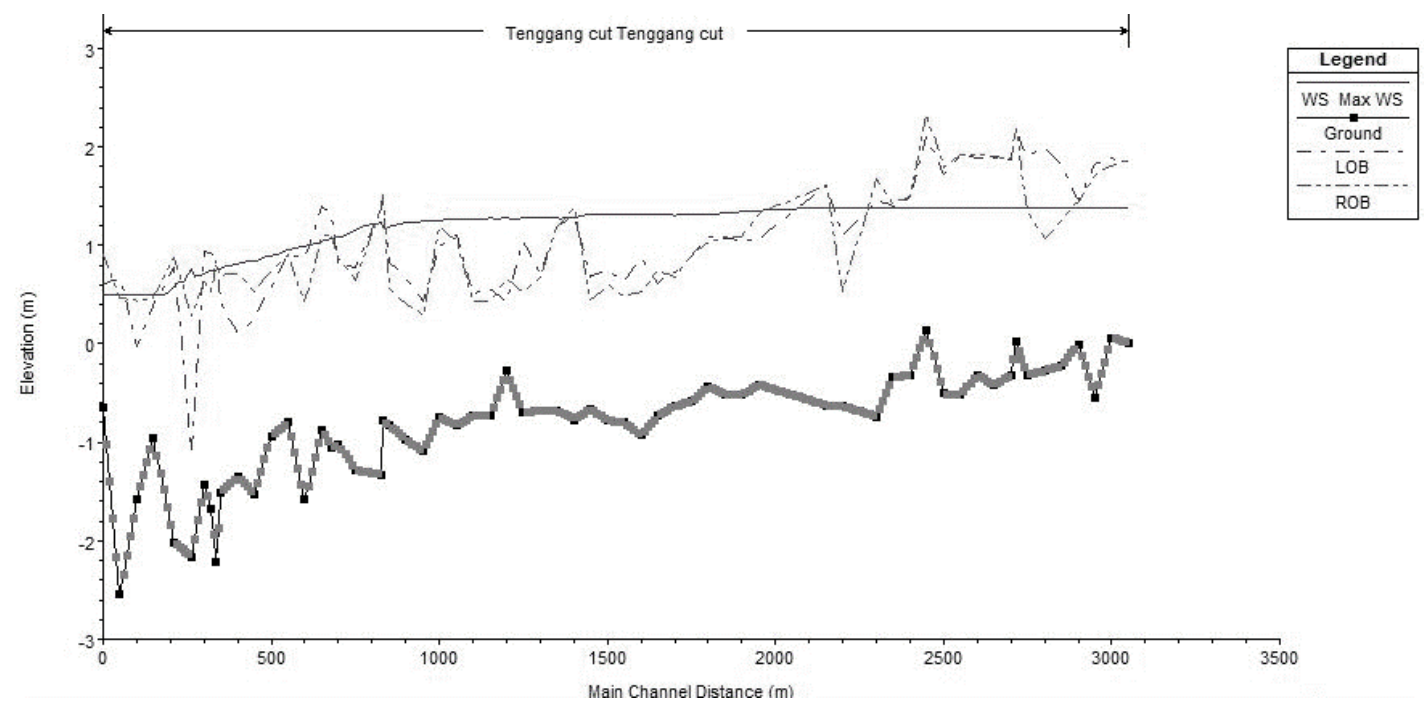

Figure 9. Water surface profile of existing condition of Tenggang River 


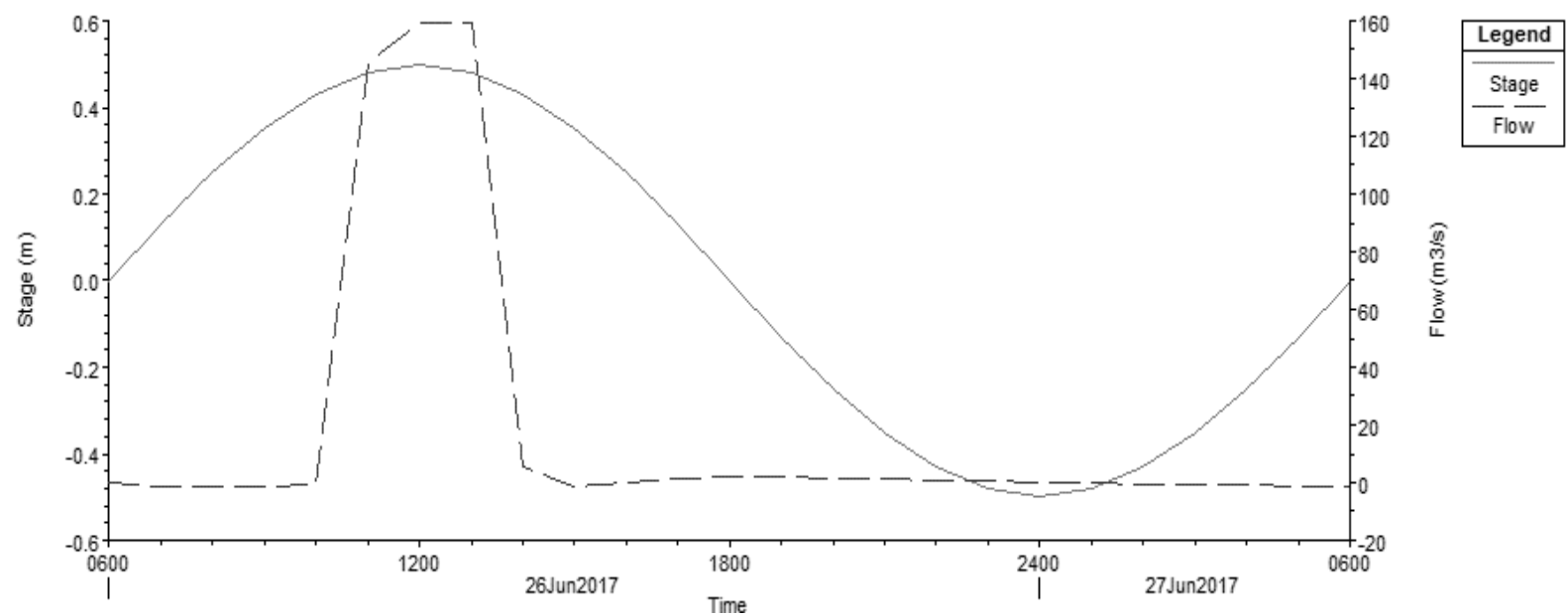

Figure 10. Flow and stage at downstream of Tenggang River.

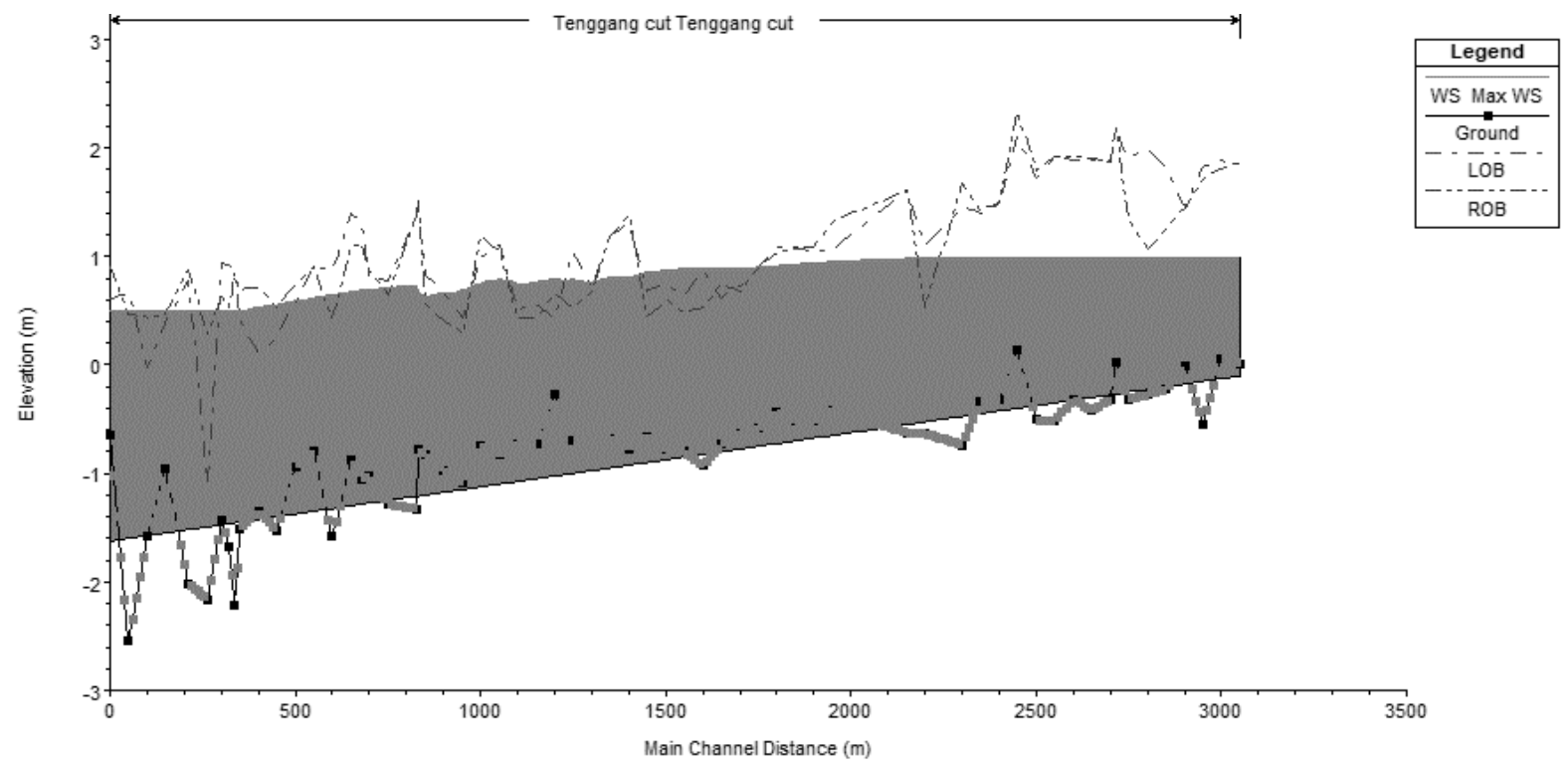

Figure 11. Water surface profile after normalizing river bed.

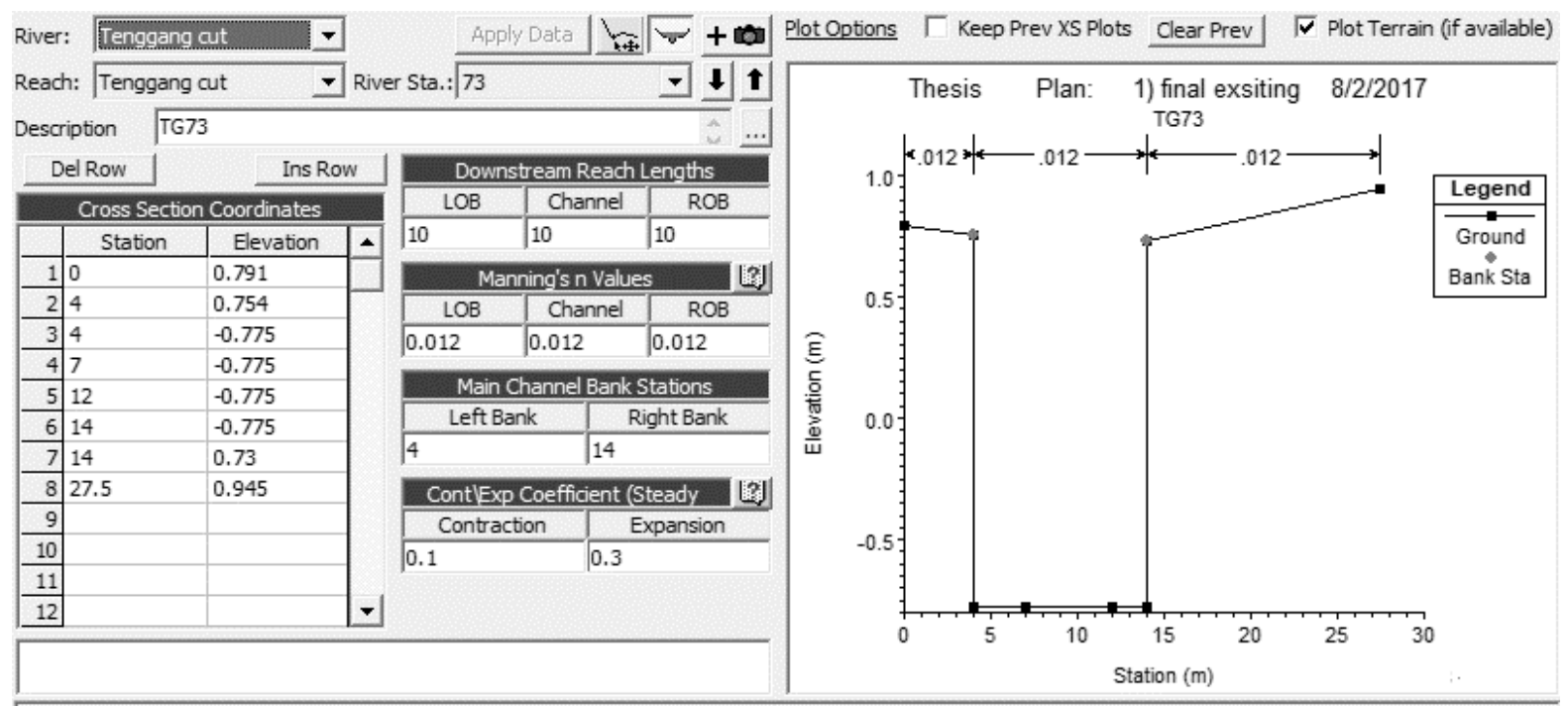

Figure 12. Cross section of Tenggang River RS 73. 


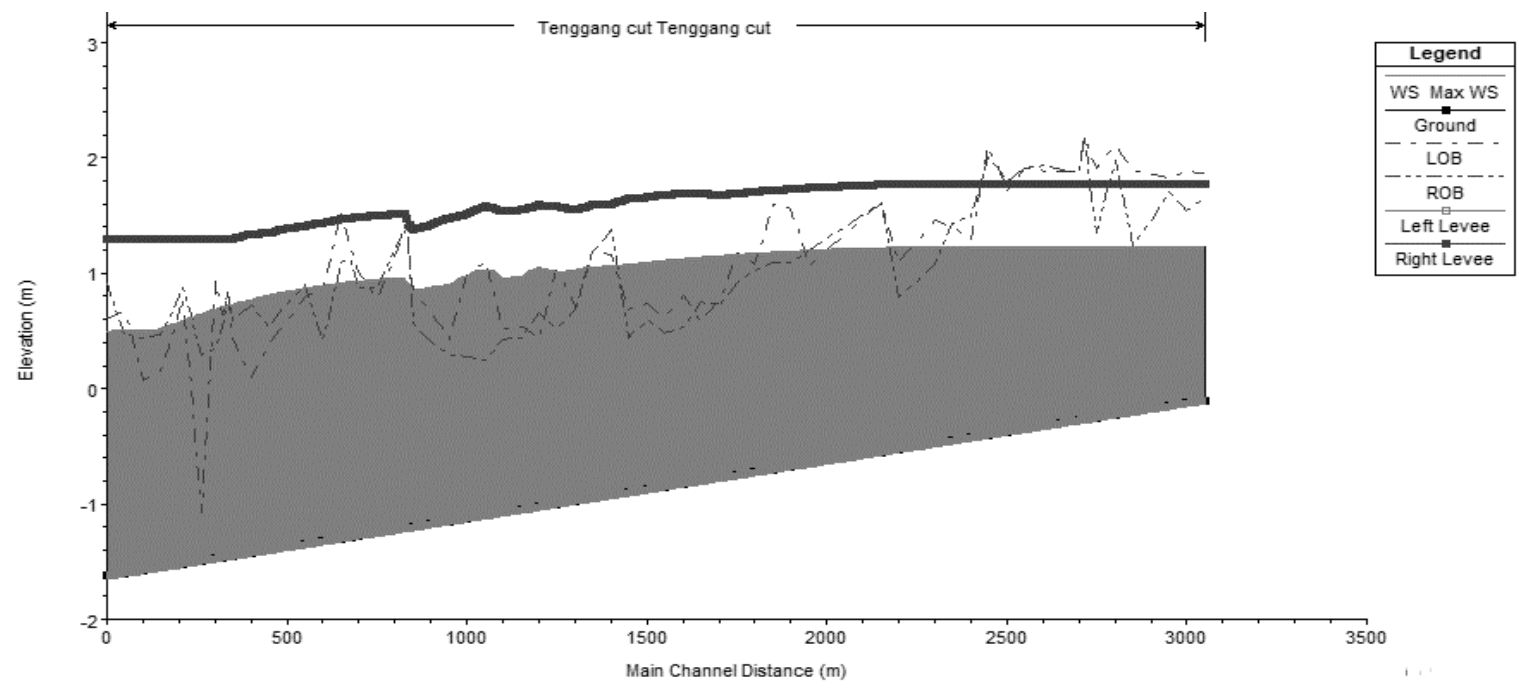

Figure 13. Water surface profile of design condition.

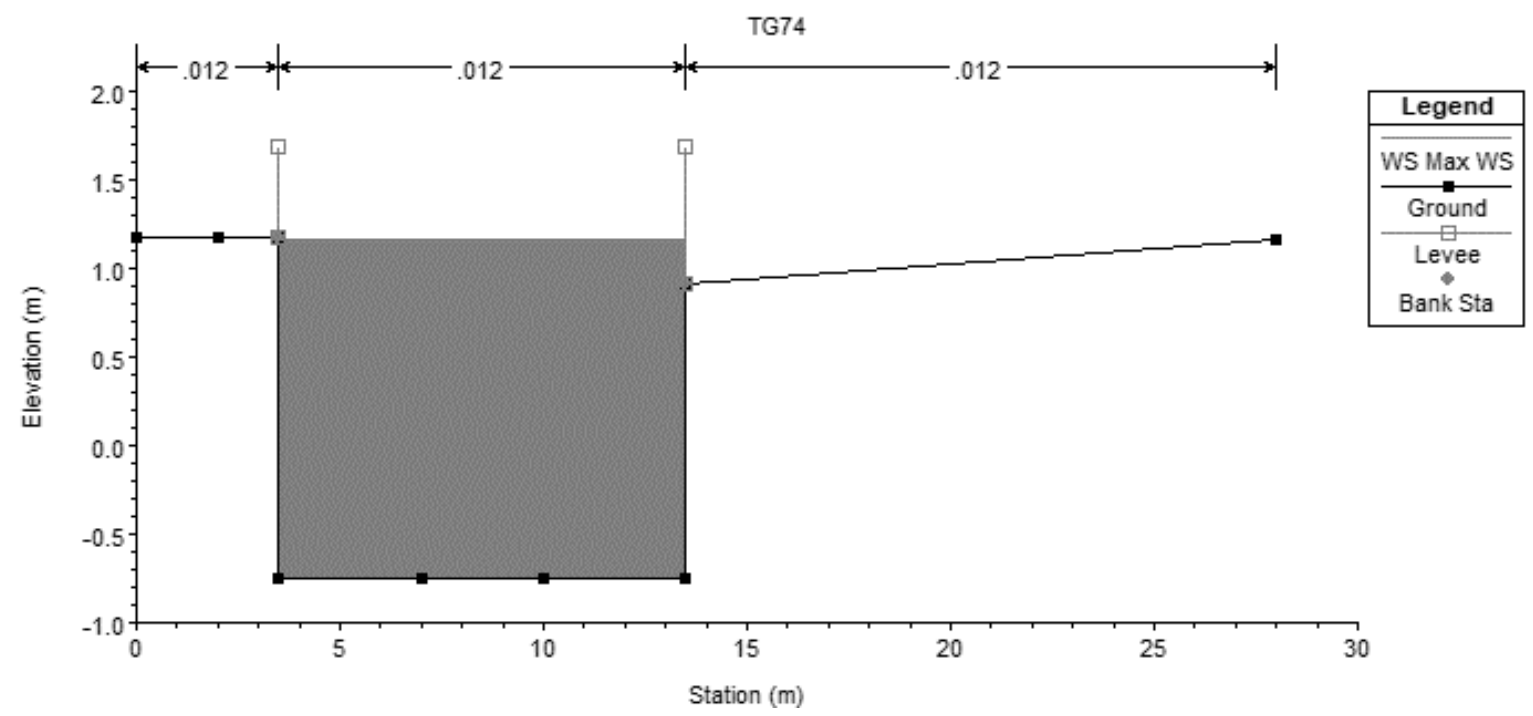

Figure 14. Cross section TG.74 of Tenggang in design condition.

\subsection{Discussion}

After getting the result from designing the main channel for flood 25 years return period with getting the result from the Ministry of public work by PT. Virama Karya Company. Both results are quite different. Table 3 shows the comparison between the report of designing channel for flood 25 years return period with our research result.

Table 3. Comparison between report and design study

\begin{tabular}{lll}
\hline Project & From report & Design study \\
\hline Design rainfall & $\begin{array}{l}\text { 25 years return } \\
\text { period }\end{array}$ & $\begin{array}{l}\text { 25 years return } \\
\text { period }\end{array}$ \\
Model application & SOBEK & HEC-RAS \\
& MODEL & MODEL \\
Free board & $\mathrm{h}=0.8 \mathrm{~m}$ & $\mathrm{~h}=0.8 \mathrm{~m}$ \\
Section of & $\mathrm{B}=10 \mathrm{~m} ; \mathrm{H}$ & $\mathrm{B}=10 \mathrm{~m} ; \mathrm{H}=2$ \\
Tenggang 100-55 & $=2.38 \mathrm{~m}$ & $\mathrm{~m}$ \\
Section of & $\mathrm{B}=20 \mathrm{~m} ;$ & $\mathrm{B}=25 \mathrm{~m} ; \mathrm{H}$ \\
Tenggang 54-39 & $\mathrm{H}=2.38 \mathrm{~m}$ & $=1.77 \mathrm{~m}$ \\
\hline
\end{tabular}

\section{CONCLUSIONS AND RECOMMENDATIONS}

\subsection{Conclusions}

The simulation concludes that improved channel condition by normalization the riverbed and increase levee can solve flood inundation at Tenggang River for 25 years with $\mathrm{Q}_{25}=119 \mathrm{~m}^{3} / \mathrm{s}$ by increasing the width of the cross-section at upstream from $7 \mathrm{~m}$ to $10 \mathrm{~m}$ and downstream from $20 \mathrm{~m}$ to $25 \mathrm{~m}$. The result of simulation shows that the result of hydrologichydraulic modeling is acceptable if compare to the report from Ministry of public work at Semarang city.

\subsection{Recommendations}

From the research, there are several miss points need to do further research in the future: 
a) Not available all data of cross section (do not have data of downstream).

b) Due to lack of data, the result is not smooth, because of the researcher need to assume some data.

c) For future research should find other solution to solve the case in that area which more accuracy and effective such as complete data and design the flood mapping to make a strategy to reduce to flood risk and increase the standard of living of people who are living around this area.

\section{REFERENCES}

Chow, v. T., Maidment, D. \& Mays, L., 1988. Applied Hydrology. New York: Mc. Graw-Hill Book Company.

Han, S. \& Coulibaly, P., 2017. Bayesian flood forecasting methods: A review. Journal of Hydrology, pp. 340-351.

Laksana, P. J., 2015. Rainfall Characteristic on the Slopes of Mount Merapi Region (Empirical Formula,
Duration, Distribution, And Critical Line Woro River). Journal of Civil Engineering Forum, 1(2), p. 43-50.

Marfai, M. A. \& King, L., 2008. Tidal inundation mapping under enhanced land subsidence in Semarang, Central Java Indonesia. Natural Hazards, 44(1), pp. 93-109.

McCuen, R. H., 1998. Hydrologic Analysis and Design. The Making of Information Systems. Prentice Hall.

Raghunath, H. M., 2006. Hydrology: Principles, Analysis and Design. New Delhi: New Age International.

Subramanya, K., 2008. Engineering Hydrology. 3rd penyunt. New York: McGraw-Hill.Inc.

Wanielista, M. P., 1990. Hydrology and Water Quality Control. Florida-USA: John Wiley \& Sons. 